\title{
Thermodynamic Analysis and Optimization of a High Temperature Triple Absorption Heat Transformer
}

\author{
Mehrdad Khamooshi, ${ }^{1}$ Kiyan Parham, ${ }^{1}$ Mortaza Yari, ${ }^{2,3}$ Fuat Egelioglu, \\ Hana Salati, ${ }^{1}$ and Saeed Babadi ${ }^{4}$ \\ ${ }^{1}$ Department of Mechanical Engineering, Eastern Mediterranean University, G. Magosa, North Cyprus, Mersin 10, Turkey \\ ${ }^{2}$ Faculty of Engineering, Department of Mechanical Engineering, University of Mohaghegh Ardabili, Ardabil 179, Iran \\ ${ }^{3}$ Faculty of Mechanical Engineering, University of Tabriz, Tabriz, Iran \\ ${ }^{4}$ Department of Electrical and Computer Engineering, University of Concordia, Montreal, QC, Canada
}

Correspondence should be addressed to Mehrdad Khamooshi; mehrdadkhamooshi@yahoo.com

Received 31 January 2014; Revised 24 June 2014; Accepted 30 June 2014; Published 17 July 2014

Academic Editor: Xuehu Ma

Copyright (C) 2014 Mehrdad Khamooshi et al. This is an open access article distributed under the Creative Commons Attribution License, which permits unrestricted use, distribution, and reproduction in any medium, provided the original work is properly cited.

First law of thermodynamics has been used to analyze and optimize inclusively the performance of a triple absorption heat transformer operating with $\mathrm{LiBr} / \mathrm{H}_{2} \mathrm{O}$ as the working pair. A thermodynamic model was developed in EES (engineering equation solver) to estimate the performance of the system in terms of the most essential parameters. The assumed parameters are the temperature of the main components, weak and strong solutions, economizers' efficiencies, and bypass ratios. The whole cycle is optimized by EES software from the viewpoint of maximizing the COP via applying the direct search method. The optimization results showed that the COP of 0.2491 is reachable by the proposed cycle.

\section{Introduction}

Pollution, carbon dioxide production, environmental hazards, and global warming are the main disadvantages of fossil fuels. Alternative choices which can assist decision makers to avoid using fossil fuels have become a big challenge nowadays. Also huge amount of low or midlevel waste heat $\left(60^{\circ} \mathrm{C}<\mathrm{T}<100^{\circ} \mathrm{C}\right)[1]$. Absorption heat transformers which are capable of upgrading the energy efficiency of industrial applications appear to be a noble choice for utilizing these waste heats. They are systems that operate in a cycle opposite to that of absorption heat pumps (AHPs). Due to the fact that the fundamental of the AHTs is close to AHPs, absorption heat transformers will have the same advantages of the absorption systems such as quite operation, less maintenance requirement, less mechanical work input, and simple design [1-7].

The amount of gross temperature lift (GTL) basically depends on the additional stages added to the single absorption heat transformers (SAHTs). Table 1 shows the coefficient of performance (COP) and GTL of the different types of absorption heat transformers.

The system performance of the SAHTs with different configurations using $\mathrm{LiBr} / \mathrm{H}_{2} \mathrm{O}$ was presented by Horuz and Kurt [1]. They reported some enhancements in the COP of the SAHTs for modified configurations. Parham et al. [8] continued and optimized their work [1] and integrated them into a desalination system. They studied the effects of some major parameters such as heat source temperature, main components temperature, flow ratio on the performance of the systems, and fresh water production rate. Khamooshi et al. [9] conducted a similar research and coupled six different configurations of triple absorptions heat transformers into desalination systems. Zare et al. [10] proposed a new combined cogeneration system consisting of two organic Rankine cycles (ORCs) and a single absorption heat transformer. The required power for this system was provided by the waste heat of a gas turbine-modular helium reactor (GT-MHR). They demonstrated that the COP and the water production rate have direct relations with the heat source temperature 
of the AHT. Yari presented a novel cogeneration cycle comprised of a transcritical $\mathrm{CO}_{2}$ power cycle and a $\mathrm{LiBr} / \mathrm{H}_{2} \mathrm{O}$ single absorption heat transformer [11]. The maximum water production rate of $3.317 \mathrm{~kg} / \mathrm{s}$ was acquired by the cycle. Sözen and Yücesu [6] performed a mathematical simulation in order to compare the absorption heat transformers utilizing ejectors to the basic AHTs. Both cycles used $\mathrm{H}_{2} \mathrm{O} / \mathrm{NH}_{3}$ as the working pair and employed the waste heat from a solar pond. The results demonstrated that both energy and exergy efficiency improvements were achievable by using ejector in the absorption heat transformer.

Siqueiros and Romero conducted two studies about recycling energy with and without increasing heat source temperature in AHT systems [12, 13]. They noticed some improvements in the proposed cycles than that of simple absorption heat transformer. Performance evaluation of the absorption heat transformers is possible by using artificial neural network analysis $[14,15]$. Zhao et al. [16, 17] conducted a study to analyze three different configurations of double absorption heat transformers by the working pairs of $\mathrm{LiBr} / \mathrm{H}_{2} \mathrm{O}$. They concluded that the temperature of the absorbing evaporator is not an independent variable and mainly depends on the absorber temperature.

First and second law analysis of a double absorption heat transformer operating with $\mathrm{LiBr} / \mathrm{H}_{2} \mathrm{O}$ were studied by Martínez and Rivera [18]. They formulated a mathematical model for estimating the COP, ECOP, total exergy destruction in the system, and exergy destruction in all the components as a function of temperature. Horuz and Kurt [19] investigated and compared single, series, and parallel double absorption heat transformers. They proved that the parallel double AHT system could generate more water vapor than that of the series double AHT system. A performance comparison of the single effect and double effect absorption heat transformer systems was made by Gomri [20]. The results showed that the double effect absorption heat transformers (DAHTs) had higher exergy and energy efficiencies and smaller water production than that of the single effect absorption heat transformers (SAHT). Also they discussed a solar absorption heat transformer coupled to a desalination system in a different study [21]. The proposed system could produce fresh water of $500 \mathrm{~L}$ per day in July for a beach house.

The performance of the absorption cycles depends not only on their configuration, but also on thermodynamic properties of working pairs which are regularly composed of refrigerants and absorbents [22]. A comparison was made between $\mathrm{H}_{2} \mathrm{O} / \mathrm{NH}_{3}$ and $\mathrm{LiBr} / \mathrm{H}_{2} \mathrm{O}$ solutions in single absorption heat transformer by Horuz [23]. Sun et al. [24] conducted a review study about different kinds of working pairs in absorption cycles. Furthermore, Khamooshi et al. [25] did a similar work for employed ionic liquids as working fluids. The same team published their second review paper wherein AHTs, from the view point of applications, crystallization risk, working fluids, performance evaluation, and economic aspects were reviewed comprehensively [26].

Donnellan et al. [27] introduced six different configurations of triple absorption heat transformers using $\mathrm{LiBr} / \mathrm{H}_{2} \mathrm{O}$
TABLE 1: System performances of different types of absorption heat transformers.

\begin{tabular}{llcc}
\hline Type & GTL & COP & Reference \\
\hline $\begin{array}{l}\text { Single absorption heat } \\
\text { transformer (SAHT) }\end{array}$ & $50^{\circ} \mathrm{C}$ & $\sim 0.5$ & {$[1,8,19]$} \\
\hline $\begin{array}{l}\text { Double absorption heat } \\
\text { transformer (DAHT) }\end{array}$ & $80^{\circ} \mathrm{C}$ & $\sim 0.35$ & {$[16-19]$} \\
\hline $\begin{array}{l}\text { Triple absorption heat } \\
\text { transformer (THAT) }\end{array}$ & $\sim 140$ & $\sim 0.23$ & {$[27,28]$} \\
\hline
\end{tabular}

as the working fluid. They optimized the number and locations of the heat exchangers within the system by reassembling them. In the second work, a rigorous multidimensional analysis was made for evaluating the performance of the triple absorption heat transformers by Donnellan et al. [28].

In this study a triple absorption heat transformer will be represented with a modified configuration described by Donnellan et al. [27]. However, their study did not investigate the effect of some major parameters on the performance of the system.

A thorough and comprehensive thermodynamic analysis will be performed for the best configuration of the latter mentioned study by the purpose of continuing it. A parametric study will be carried out and validated by other studies available from the literature in order to identify the effects of some parameters such as the temperatures of the condenser, evaporator, absorber, generator, first absorber/evaporator $(\mathrm{AB} / \mathrm{EV} 1)$ and second absorber/evaporator (AB/EV2), concentration of the weak and strong solution, and economizer effectiveness.

\section{System Description}

Figure 1 shows the general schematic of the absorption heat transformer in single stage mode. The SAHT basically consists of an evaporator, a condenser, a generator, an absorber, and a solution heat exchanger (SHE). The generator and evaporator are supplied with waste heat at the same temperature, leading to increased heat that can be collected at the absorber [26].

Refrigerant vapor is produced at state 4 in the evaporator by low or medium-grade heat source. The refrigerant vapor dissolves and reacts with the strong refrigerant-absorbent solution that enters the absorber from state 10 , and the weak solution returns back to the generator at state 5 . The heat released from the absorber will be higher than the input heat in generator and evaporator due to the exothermic reaction of $\mathrm{LiBr}$ and water in it. In the generator, some refrigerant vapor is removed from the weak solution to be sent to the condenser and, consequently, the strong solution from the generator is returned to the absorber. After condensing the vaporized refrigerant in the condenser, it is pumped to a higher pressure level as it enters the evaporator. The waste heat delivered to the evaporator causes its vaporization. Again, the absorber absorbs the refrigerant vapor at a higher temperature. Therefore, the absorption cycles have the capability of raising the 


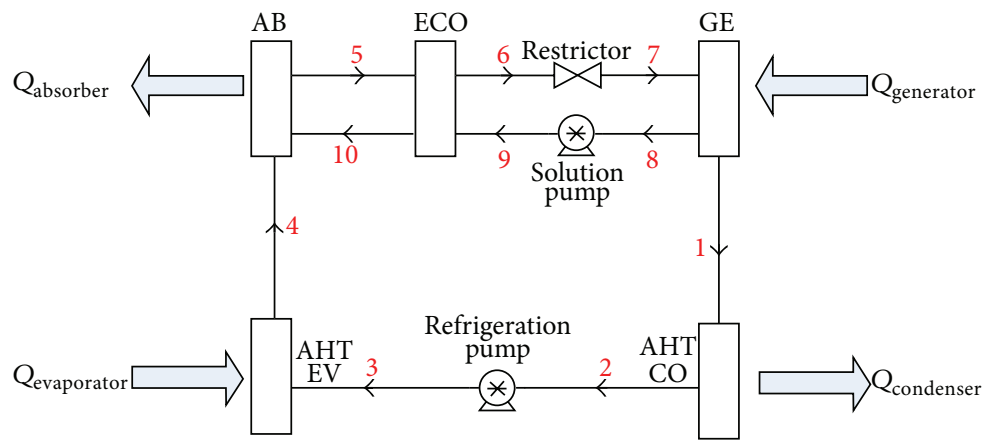

FIGURE 1: Schematic diagram of a single stage absorption heat transformer.

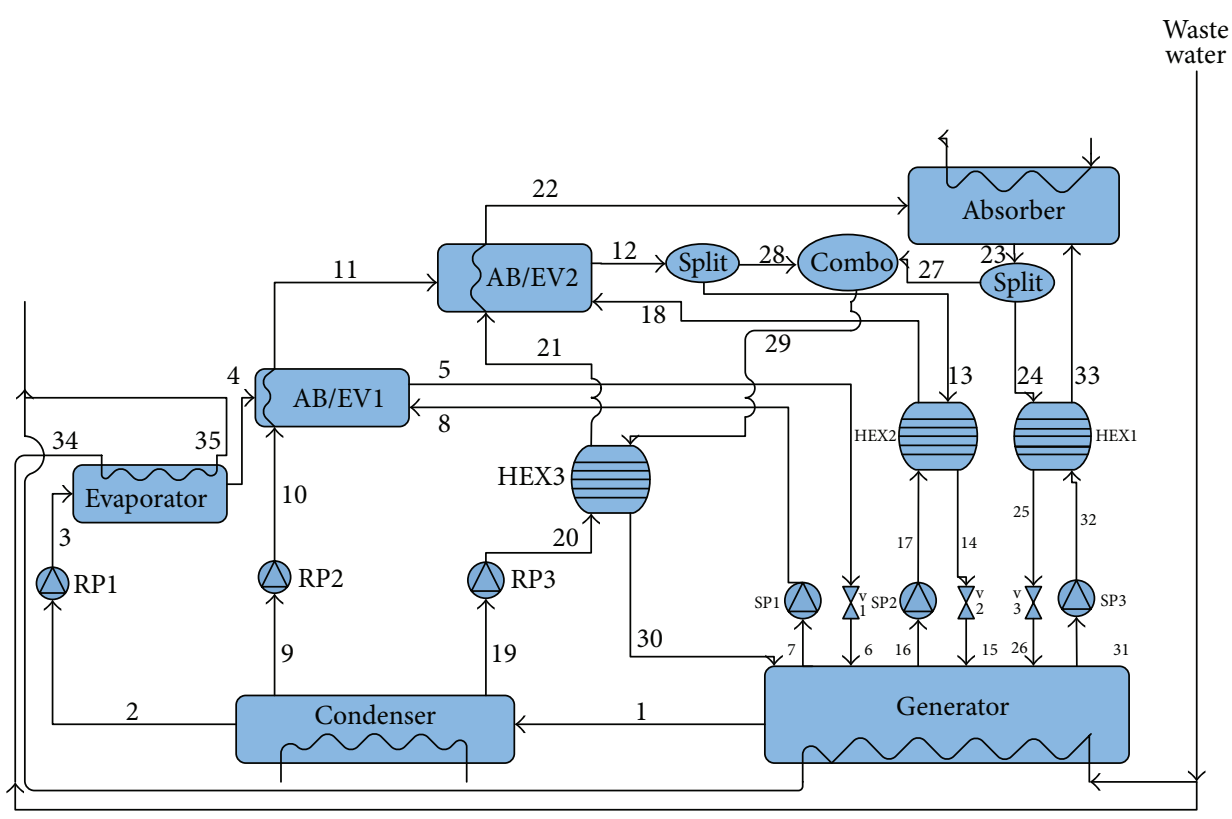

FIGURE 2: Schematic diagram of a triple absorption heat transformer.

temperature of the solution above the temperature of the waste heat [19].

Figure 2 displays the modified configuration of the triple absorption heat transformer. This cycle mainly consists of a generator, a condenser, an evaporator, an absorber, two absorber/evaporators, and three economizers. In this system heat is transferred to the evaporator and the generator from the waste hot water of a textile factory at the same time. The rejected heat from the absorber provides the thermal energy demanded by the desalination system. Superheated water vapor which works as refrigerant comes out from the generator and enters to the condenser where it is condensed as saturated liquid. One part of the condensed refrigerant is pumped to the higher pressure level of the evaporator $\left(P_{1}\right)$. In the evaporator, water is heated to saturated vapor phase with the same waste heat provided to the generator. This vapor is absorbed in the first absorber/evaporator by the strong solution of $\mathrm{LiBr} / \mathrm{H}_{2} \mathrm{O}$ coming back from the generator. One portion of the released heat in the absorber is used to retain the absorber-evaporator- 1 at a temperature higher than that of the evaporator. The second split of the condensed refrigerant leaving the condenser is pumped to the pressure level of $P_{2}$ which is higher than that of $P_{1}$ and provides heat to the saturated vapor by utilizing the heat of the absorption preserved by $\mathrm{AB} / \mathrm{EV} 1$. This vapor is then absorbed in $\mathrm{AB} / \mathrm{EV} 2$ by the strong $\mathrm{LiBr} / \mathrm{H}_{2} \mathrm{O}$ solution flowing from the generator. Some parts of the absorption heat are used to maintain the $\mathrm{AB} / \mathrm{EV} 2$ at a temperature higher than that of $\mathrm{AB} / \mathrm{EV} 1$. The final split of the condensed refrigerant is pumped to the highest pressure level $\left(P_{3}\right)$ and consequently the water is heated in $\mathrm{AB} / \mathrm{EV} 2$ to saturated vapor by the retained heat in the $\mathrm{AB} / \mathrm{EV} 2$. Finally this saturated vapor is absorbed by the strong absorbent-refrigerant coming back from generator and the exothermic reaction in the absorber makes the temperature approximately $\left(30-60^{\circ} \mathrm{C}\right.$ [27]) hotter than that of the temperature of the $\mathrm{AB} / \mathrm{EV} 2$. The residual part of the released heat is transferred to impure water as latent and sensible heat in desalination system as shown in Figure 2. The weak solutions coming back from the absorber and $\mathrm{AB} / \mathrm{EV} 2$ are divided into two parts. One part of each is 
directly returned to generator and used in heat recovery part of the first and second heat exchanger. The second fractions of the weak solution are combined together in order to be used in heat recovery part of the third heat exchanger.

\section{Thermodynamic Analysis}

The following section describes the thermodynamics model used for simulation of the TAHT. Each component of the considered system has been treated as a control volume and the principles of mass and energy conservation are applied to them. EES software is used for solving the equations [32].

3.1. Assumption. The following assumptions have been made in the analysis.

(1) Changes in kinetic and potential energies are neglected $[8,27,28]$.

(2) The pressure losses due to the frictional effects in the connecting pipes of the AHT are neglected $[8,18,27$, 28].

(3) The system is in thermodynamic equilibrium and all the processes are assumed to be steady flow processes $[8,18,27,28]$.

(4) Some proper values of effectiveness are considered for the heat exchangers $[8,18]$.

(5) In the TAHT, the solution at the generator and the absorber outlets, as well as the refrigerant at the condenser and the evaporator outlets, is all at saturated states $[8,18,27,28]$.

(6) The salt utilized in the absorbent solution is assumed to have negligible vapor pressure $[27,28]$.

(7) Heat losses from components are very small relative to heat fluxes and are thus not included in the model $[27,28]$.

(8) The evaporator and the generator of the AHT work at the same temperature [8].

(9) The refrigerant vapor is assumed to evaporate and condense completely in the two absorberevaporators, the evaporator, and the condenser [27, 28].

(10) The heat source for the AHT system is the hot water generated by a cogeneration system in a textile company. The industrial system has four different units each of them producing 15 ton/h water at $90 \pm$ $2^{\circ} \mathrm{C}[1,8]$.

(11) The mechanical energy consumed by pumps can be neglected [8].

3.2. Performance Evaluation. Table 2 summarizes the basic assumptions and used input parameters in the simulation.

The system's COP is determined as the ratio of useful heat output systems over the systems input energy. Due to the fact that COP is the most important criterion of the cycle's capability for upgrading the delivered thermal energy to the
TABLE 2: The input data of simulation.

\begin{tabular}{lc}
\hline Parameters & Value \\
\hline$T_{\text {con }}\left({ }^{\circ} \mathrm{C}\right)$ & $20-35^{\mathrm{a}}$ \\
$T_{\text {abs }}\left({ }^{\circ} \mathrm{C}\right)$ & $180-215^{\mathrm{b}}$ \\
$T_{\text {eva }}\left({ }^{\circ} \mathrm{C}\right)$ & $80-110^{\mathrm{c}}$ \\
$T_{\text {eva }}=T_{\text {gen }}\left({ }^{\circ} \mathrm{C}\right)$ & $\mathrm{d}$ \\
$T_{\mathrm{AB} / \mathrm{EV} 1}\left({ }^{\circ} \mathrm{C}\right)$ & $110-145^{\mathrm{e}}$ \\
$T_{\mathrm{AB} / \mathrm{EV} 2}\left({ }^{\circ} \mathrm{C}\right)$ & $150-180^{\mathrm{e}}$ \\
$T_{\text {heat source }}\left({ }^{\circ} \mathrm{C}\right)$ & $90 \pm 2^{\circ} \mathrm{C}^{\mathrm{f}}$ \\
m-dot heat source $($ ton $/ \mathrm{h})$ & $60^{\mathrm{f}}$ \\
$\varepsilon_{\mathrm{ECO}}(\%)$ & $80^{\mathrm{g}}$ \\
\hline
\end{tabular}

The values are obtained from various studies such as a [29-31], b [27, 28], c [27],d $[8,12,13,20,21]$, e $[27,28], \mathrm{f}[1,8], \mathrm{g}[8,20,21]$.

system, it plays an important role in analyzing the absorption cycles. The COP is given in the following equation [33-35]:

$$
\mathrm{COP}=\frac{Q_{\mathrm{abs}}}{Q_{\text {gen }}+Q_{\text {eva }}} .
$$

Another fundamental parameter for designing and optimizing the absorption cycles is the flow ratio. It is defined as the ratio of the total mass flow rate of weak solution entering the generator to the mass flow rate of refrigerant vapour leaving the generator [27]:

$$
f=\frac{\text { mass flow of salt solution entering the generator }}{\text { mass flow of vapour leaving the generator }} \text {. }
$$

The heat capacities of the main components of the cycles are as follow:

$$
\begin{gathered}
Q_{\text {eva }}=\dot{m}_{34}\left(h_{34}-h_{35}\right)=\dot{m}_{4}\left(h_{4}-h_{3}\right), \\
Q_{\text {gen }}=\dot{m}_{1} h_{1}+\dot{m}_{7} h_{7}+\dot{m}_{16} h_{16}+\dot{m}_{31} h_{31}-\dot{m}_{6} h_{6} \\
-\dot{m}_{15} h_{15}-\dot{m}_{30} h_{30}, \\
Q_{\text {con }}=\dot{m}_{1} h_{1}-\dot{m}_{2} h_{2}-\dot{m}_{9} h_{9}-\dot{m}_{19} h_{19}, \\
Q_{\mathrm{abs}}=\dot{m}_{22} h_{22}+\dot{m}_{33} h_{33}-\dot{m}_{23} h_{23}, \\
Q_{\mathrm{AB} / \mathrm{EV} 1}=\dot{m}_{10}\left(h_{11}-h_{10}\right)=\dot{m}_{4} h_{4}+\dot{m}_{8} h_{8}-\dot{m}_{5} h_{5}, \\
Q_{\mathrm{AB} / \mathrm{EV} 2}=\dot{m}_{22}\left(h_{22}-h_{21}\right)=\dot{m}_{11} h_{11}+\dot{m}_{18} h_{18}-\dot{m}_{12} h_{12} .
\end{gathered}
$$

The heat capacity of absorber also can be calculated by using the equation below $[1,19]$ :

$$
q_{\mathrm{abs}}=\frac{Q_{\mathrm{abs}}}{\dot{m}_{4}}=(f+1) h_{23}-f h_{22}-h_{33} \text {. }
$$

Bypass ratio is an imperative parameter defined for the weak solutions coming back from the absorber and AB/EV2 defined as

$$
\begin{aligned}
& \mathrm{BP} 1=\frac{m_{24}}{m_{27}}, \\
& \mathrm{BP} 2=\frac{m_{13}}{m_{28}} .
\end{aligned}
$$


3.3. Optimization Method. The cycle's performance fundamentally depends on temperature of the main components; therefore the optimum COP of the cycles can be expressed as follows:

$$
\begin{array}{ll}
\text { Maximize COP } & \left(T_{\mathrm{abs}}, T_{\mathrm{gen}}, T_{\mathrm{con}}, T_{\mathrm{AB} / \mathrm{EV} 1}, T_{\mathrm{AB} / \mathrm{EV} 2}, T_{\mathrm{eva}}\right) \\
\text { Subject to: } & 20 \leq T_{\mathrm{con}} \leq 35^{\circ} \mathrm{C} \\
& 90 \leq T_{\mathrm{eva}} \leq 105^{\circ} \mathrm{C} \\
& 90 \leq T_{\mathrm{gen}} \leq 105^{\circ} \mathrm{C} \\
& 110 \leq T_{\mathrm{AB} 1} \leq 145^{\circ} \mathrm{C} \\
& 165 \leq T_{\mathrm{AB} 2} \leq 180^{\circ} \mathrm{C} \\
& 180 \leq T_{\mathrm{abs}} \leq 215^{\circ} \mathrm{C} .
\end{array}
$$

By applying the constraint for each variable and by setting bounds, the performance of the whole cycle is optimized by EES software from the viewpoint of maximizing the COP.

Direct search method is best known as unconstrained optimization technique that does not explicitly use derivatives [36].

3.4. Model Validation. The available data in the literature were used to validate the simulation results. For the case of the AHT cycle the experimental results reported by Rivera et al. [31] are used. The conditions and assumptions used in their work are applied for the aim of validation. The assumptions are as follows.

(I) Heat losses and pressure drops in the connecting pipes and the components are considered negligible.

(II) The flow through the expansion valves is isenthalpic.

(III) The effectiveness of the economizer is $70 \%$.

(IV) The absorber temperature is $123^{\circ} \mathrm{C}$.

(V) The generator and evaporator temperatures being the same are $74.1^{\circ} \mathrm{C}$

Figure 3 shows the comparison between the COP obtained from the present work with that reported by Rivera et al. [31] The figure shows an excellent agreement between the two and indicates a decrease in the COP as the condenser temperature of the AHT system increases.

The available result in the Donnellan et al.s [27] work was also used to validate the simulation. The similarity between Figures 4 and 5 verifies the validity of our simulations. Likewise, the obtained COP of the system is qualitatively in agreement with the latter mentioned study.

In Figures 4 and 5 it is evident that as $T_{\text {eva }}$ is higher than $105^{\circ} \mathrm{C}$, COP drops and there is a satisfactory agreement between them.

\section{Results and Discussion}

Figures 6 and 7 show the variation of the COP by the first and second Bypass ratios. It is clear that the COP is higher

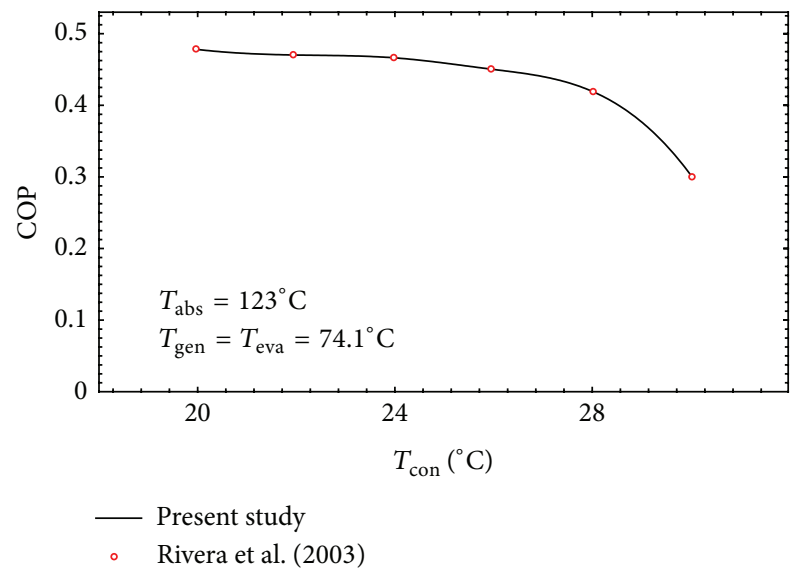

FIGURE 3: Validation of the simulation model developed for AHT system.

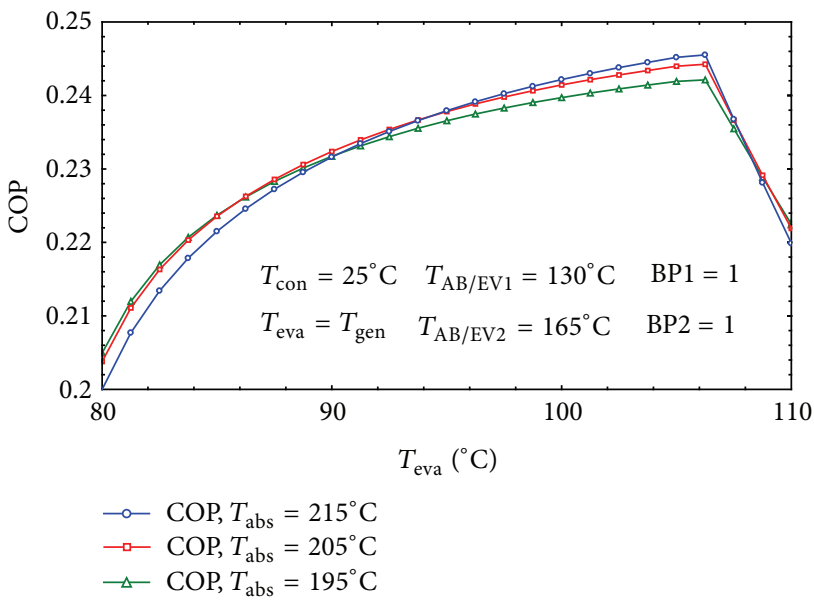

FIGURE 4: Effect of $T_{\text {eva }}$ on the COP of the system.

for smaller amounts of BP1 and higher quantities of BP2. This means that the temperature of the point 29 will become higher with considered amounts of bypass ratios which leads to increasing heat recovery in the third heat exchanger. This is in agreement with those reported in [27] whom stated the fact that the third heat exchanger has a much greater influence on the cycle's performance than any other heat exchanger.

As it can be seen in Figure 8 when $T_{\text {eva }}$ which is equal to $T_{\text {gen }}$ increases, the COP would also increase. This is due to the fact that the maximum pressure of the system has direct relation with the evaporator's temperature. By increasing the maximum pressure of the system the weak solution concentration will decrease by decreasing flow ratio. The lower flow ratio means higher absorber heat capacity and the higher COP. This result achieves harmony with those reported in $[1,10,19,27]$. Also it is clear that as the gross temperature lift ( GTL $=T_{\text {abs }}-T_{\text {eva }}$ ) decreases the COP and increases rapidly. From the first law of thermodynamics it is explicit that the system has to reduce its efficiency as the absorber increases its temperature which is in accordance with the results available in $[8,27,37,38]$. 


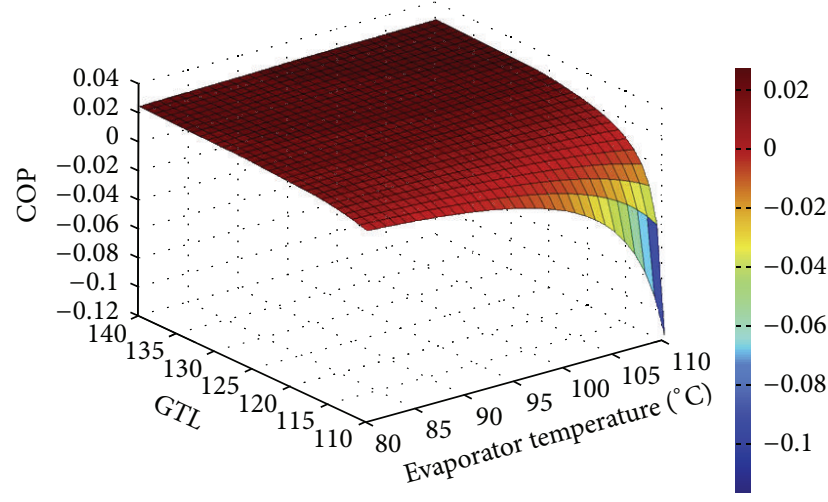

Figure 5: Effect of $T_{\text {eva }}$ on the COP of the system [27].

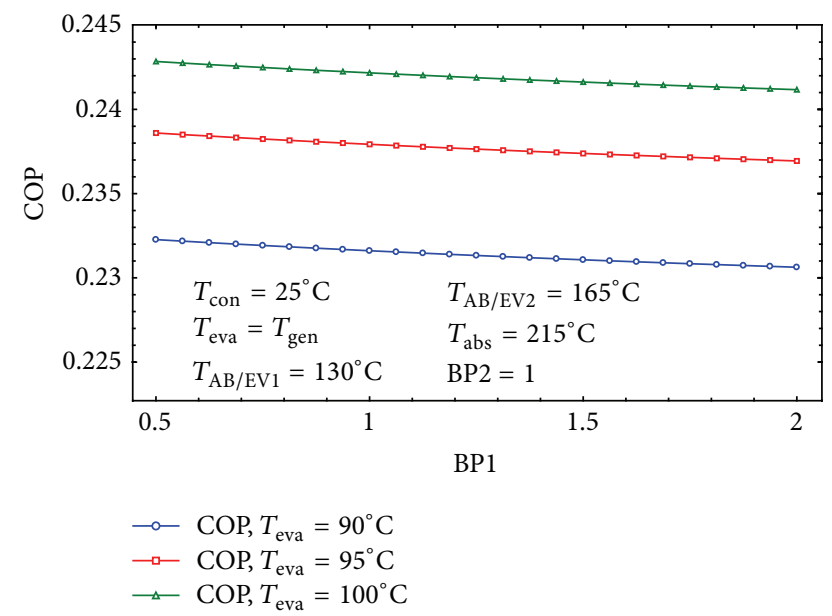

FIGURE 6: The effect of BP1 on the COP of the cycle for three different $T_{\text {eva }}$.

Figure 9 depicts the variation of COP with $T_{\text {abs }}$ in three different evaporator temperatures. It is clear that it has a similar trend with that of Figure 8 which shows the decreasing behavior of COP by increasing GTL. Also by increasing $T_{\mathrm{abs}}$, the concentration of the weak solution and consequently the flow ratio increase which leads into a decrease in the absorber heat capacity $[8,10,20,39]$.

Figure 10 shows the effect of condenser's temperature on the COP of the system. This is by reason of the fact that the minimum system pressure raises with increasing the condenser temperature. By boosting the $T_{\text {con }}$ the strong solution concentration will go down which increases the flow ratio of the system. The bigger flow ratio will result in the lower absorber heat capacity and lower COP [19]. Figure 10 proposes that the condensation temperature should always be kept at its lowest setting [28] and the system has its best performance during the winter.

Concentration of the working pair in the system can be classified into two categories: firstly, strong solution which is the concentration of the solution flowing from generator to absorber $\left(X_{31}\right)$ and secondly the weak solution that is

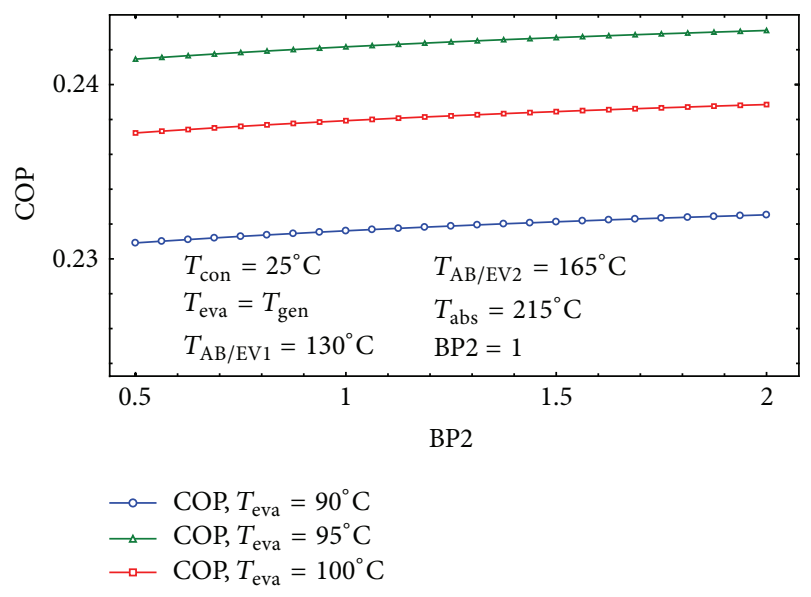

FIGURE 7: The effect of BP2 on the COP of the cycle for three different $T_{\text {eva }}$.

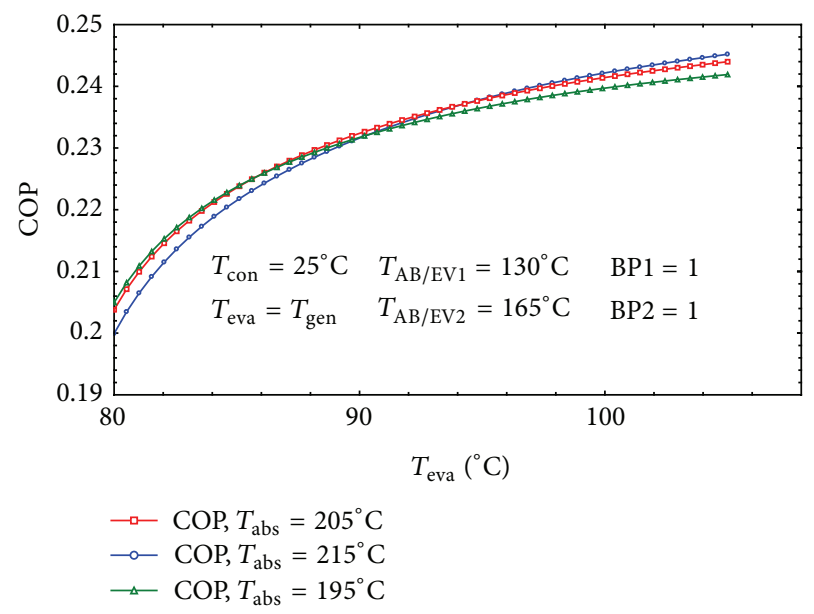

FIGURE 8: The effect of $T_{\text {eva }}$ on the COP of the cycle for three different $T_{\text {abs. }}$.

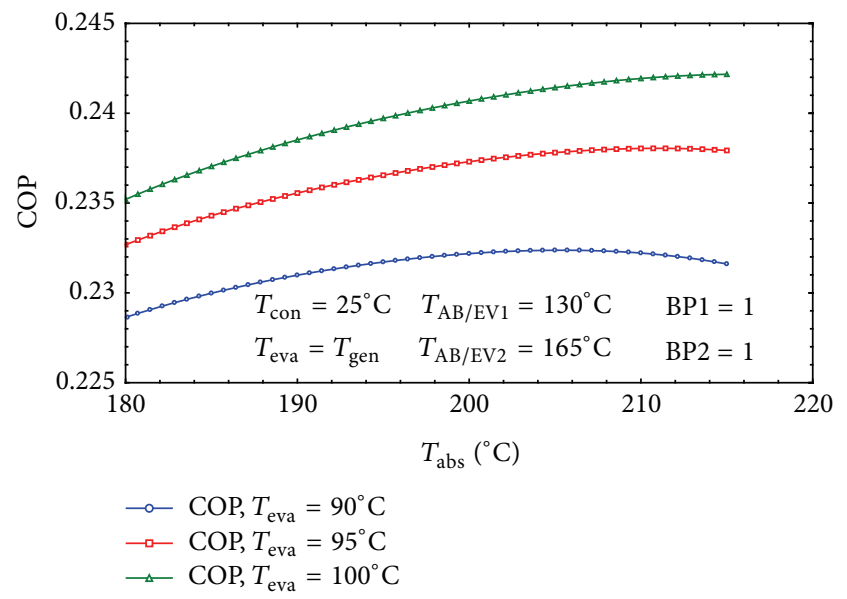

FIGURE 9: The effect of $T_{\text {abs }}$ on the COP of the cycle for three different $T_{\text {eva }}$. 


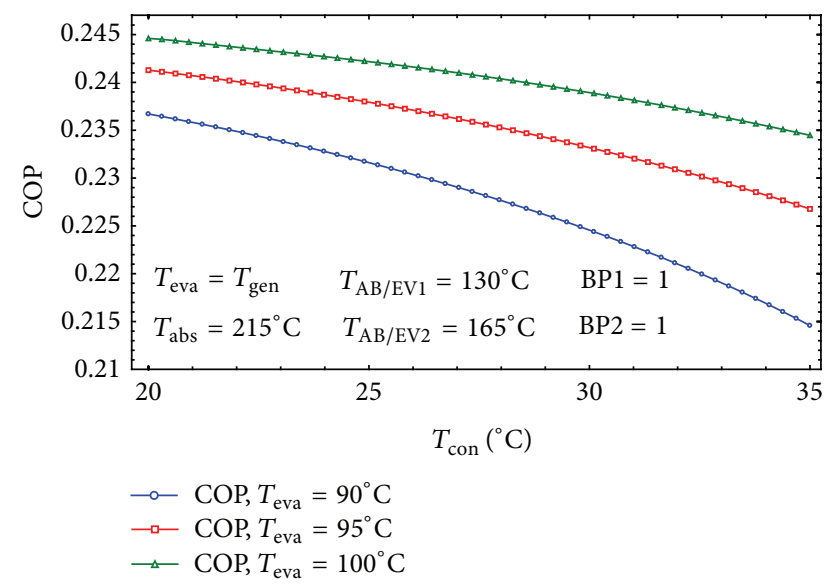

Figure 10: The effect of $T_{\text {con }}$ on the COP of the cycle for three different $T_{\text {eva }}$.

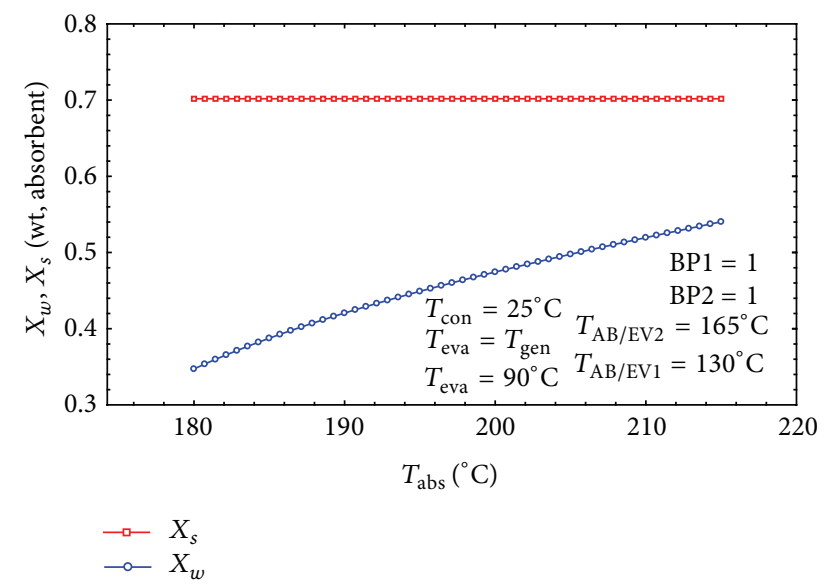

Figure 11: The effect of $T_{\mathrm{abs}}$ on the concentration of the strong and weak solution.

the concentration of the solution coming back from the absorber to the generator $\left(X_{23}\right)$.

In Figure 11 both $X_{s}$ and $X_{w}$ are plotted against the absorber temperature. It is obvious that when generating, condensing, and absorber/evaporator temperatures are kept constant, $X_{s}$ does not vary with $T_{\mathrm{abs}}$, but the $X_{w}$ is increasing. The higher the evaporator or generator temperature is, the bigger the strong solution is. Consequently the higher $X_{s}$ results in the higher flow ratio and can also increase the amount of the demanded heat input into the cycle [1].

The concentration difference $\left(\Delta X=X_{s}-X_{w}\right)$ exhibits a parabolic decrease by increasing absorber temperature as shown in Figure 12. As mentioned correspondingly in the literature $[8,10,40]$, when generation, evaporation, $\mathrm{AB} / \mathrm{EV}$, and condensing temperatures are constant, the $\Delta X$ and $T_{\text {abs }}$ will only vary with $f$, which is an important and easily controllable operation parameter. Larger $f$ also results in higher $T_{\mathrm{abs}}$ and more mechanical power losses. This is completely in agreement with the results of Horuz and Kurt

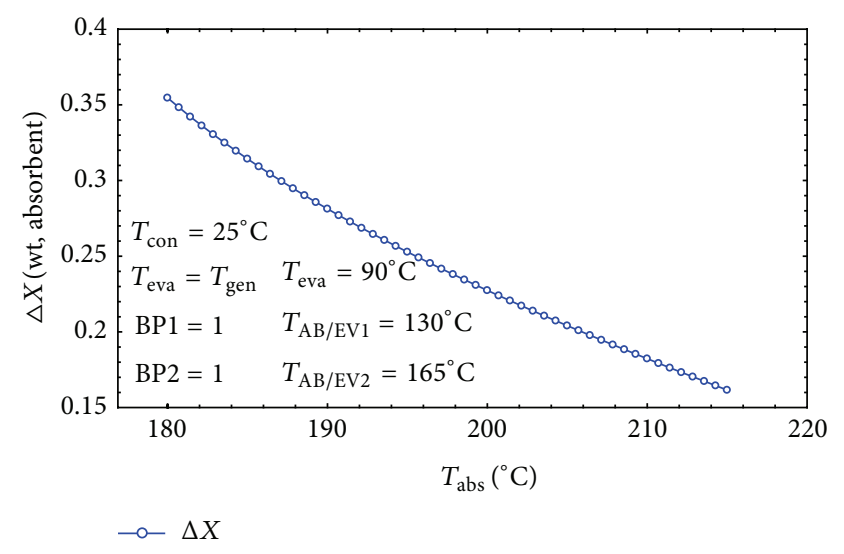

FIGURE 12: The effect of $T_{\mathrm{abs}}$ on $\Delta x$.

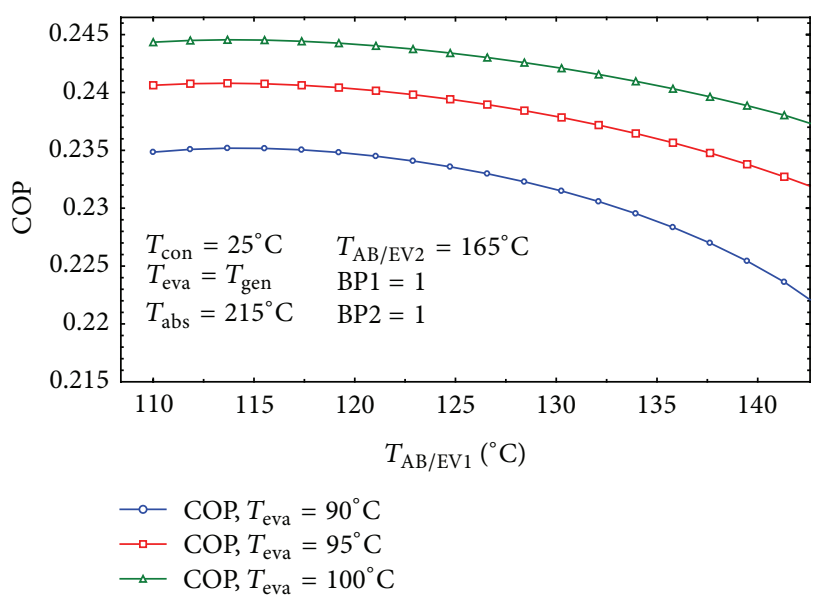

Figure 13: The effect of $T_{\mathrm{AB} / \mathrm{EV} 1}$ on COP of the system.

[1] which proved that if the evaporator temperature is bigger, the AHT performs better.

The effects of $T_{\mathrm{AB} / \mathrm{EV} 1}$ and $T_{\mathrm{AB} / \mathrm{EV} 2}$ on the COP of the system have been shown in Figures 13 and 14 for the considered settings. In Figure 13 the $\mathrm{COP}$ is at the highest value within the midpoint temperature of $T_{\mathrm{AB} / \mathrm{EV} 1}$. But as demonstrated in Figure $14 T_{\mathrm{AB} / \mathrm{EV} 2}$ should remain as low as possible in order to achieve maximum COP.

In Figure 15 the COP is plotted against heat exchanger efficiencies $(\varepsilon)$. It is obviously evident that $\varepsilon$ has a major role on the COP of the system. The variation of the economizer effectiveness can increase the COP up to $21 \%$. It can be concluded that the effectiveness of the economizers should be as high as possible, that is, a reasonable result according to the heat transfer phenomenon.

4.1. A General Comparison among Different Configurations of AHTs. In our previous work [26] the variation of COP with gross temperature lift under different evaporation temperature conditions was compared for single, double, and triple AHTs, using $\mathrm{LiBr} / \mathrm{H}_{2} \mathrm{O}$ the working fluid. As seen in Figure 16, any increase in GTL will cause a drop in the COP. This is due to the fact that as $T_{\mathrm{abs}}$ increases, the concentration 
TABLE 3: The results of optimization for maximum value of the COP.

\begin{tabular}{lccccccc}
\hline$T_{\text {eva }}$ & BP1 & BP2 & $T_{\text {con }}$ & $T_{\text {gen }}$ & $T_{\text {AB/EV1 }}$ & $T_{\mathrm{AB} / \mathrm{EV} 2}$ & $T_{\text {abs }}$ \\
\hline 90 & 0.5 & 1.977 & 20 & 90 & 110 & 165 & 210.5 \\
95 & 0.5 & 2 & 20 & 95 & 111 & 165 & 0.2423 \\
100 & 0.5 & 2 & 20 & 100 & 112.3 & 165 & 211.2 \\
105 & 0.5 & 2 & 20 & 105 & 115.4 & 165 & 213 \\
\hline
\end{tabular}

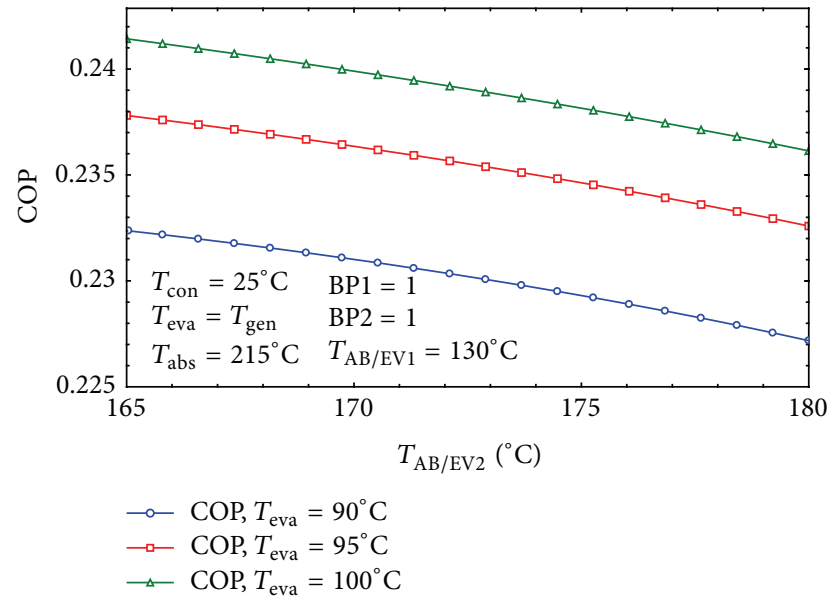

FIGURE 14: The effect of $T_{\mathrm{AB} / \mathrm{EV} 2}$ on COP of the system.

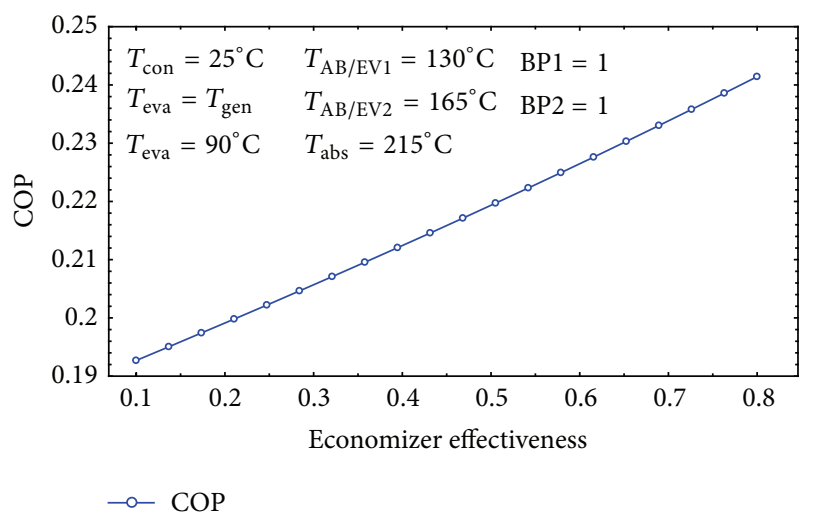

FIGURE 15: The effect of economizer on COP of the cycle.

of the weak solution and consequently the flow ratio $(f)$ increases resulting in a decrease in the absorber heat capacity. This result is in agreement with that reported in the literature $[1,8]$.

Additionally, the higher the evaporation temperature is the higher the absorption temperature and the corresponding gross temperature are. It is observed that SAHT has the highest COP and the TAHT owns the lowest. The same trend has been reported by Donnellan et al. [27].

\section{Optimization}

By using direct search method in EES software, the COP magnitude of the cycle has been optimized as a function of

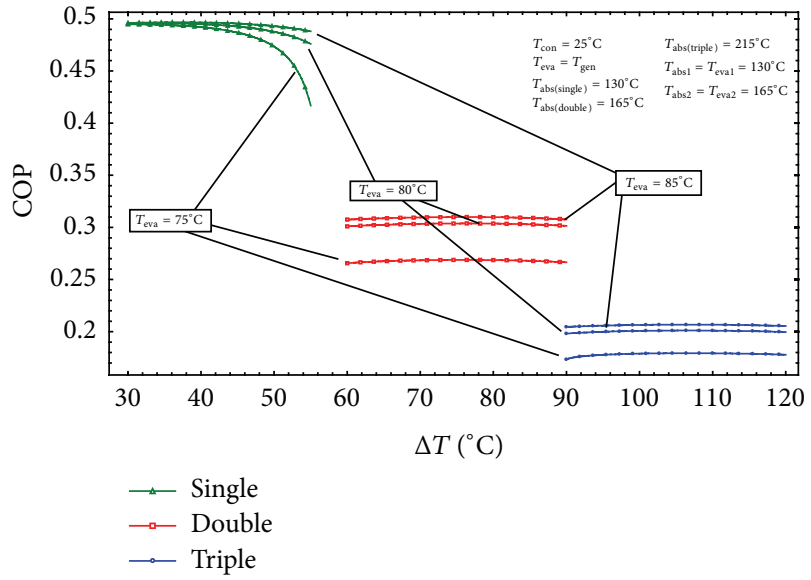

FIGURE 16: Effects of GTL on COP for different types of AHTs at different evaporation temperatures [26].

main components' temperatures. The results are summarized in Table 3. The optimization was performed for 4 different evaporator temperatures.

The results are completely in coherence with the previously discussed results in the figures. The COP has ascending trend with increasing the temperature of the evaporator as earlier in Figure 8.

As shown in Table 3 the $T_{\text {con }}$ is always at the lowest possible amount of the setting which is $20^{\circ} \mathrm{C}$ (discussed in Figure 10). Also the bypass ratios show a proper amount in comparison with Figures 6 and 7. The maximum amount of COP which is 0.2491 is obtained at the $T_{\text {eva }}=105^{\circ} \mathrm{C}$.

\section{Conclusion}

In this study a triple absorption heat transformer is proposed for waste heat recovery from the industrial processes. Thermodynamic models were developed and parametric studies were carried out. Also performances of the whole cycle were optimized for maximum COP.

It is proven that in the triple absorption heat transformer systems,

(i) the systems condensation temperature should always be kept at minimum value;

(ii) the lower gross temperature lift is, the higher the COP will be;

(iii) the third heat exchanger has a much greater influence upon the cycle's performance than the any other heat exchanger; 
(iv) single stage absorption heat transformer has the highest COP and the TAHT owns the lowest;

(v) the maximum COP of 0.2491 is obtained from the cycle.

\section{Conflict of Interests}

The authors declare that there is no conflict of interests regarding the publication of this paper.

\section{References}

[1] I. Horuz and B. Kurt, "Absorption heat transformers and an industrial application," Renewable Energy, vol. 35, no. 10, pp. 2175-2181, 2010.

[2] E. Kurem and I. Horuz, "A comparison between ammoniawater and water-lithium bromide solutions in absorption heat transformers," International Communications in Heat and Mass Transfer, vol. 28, no. 3, pp. 427-438, 2001.

[3] W. Rivera and J. Cerezo, "Experimental study of the use of additives in the performance of a single-stage heat transformer operating with water-lithium bromide," International Journal of Energy Research, vol. 29, no. 2, pp. 121-130, 2005.

[4] A. Şencan, Ö. Kizilkan, N. Ç. Bezir, and S. A. Kalogirou, "Different methods for modeling absorption heat transformer powered by solar pond," Energy Conversion and Management, vol. 48, no. 3, pp. 724-735, 2007.

[5] S. Smolen and M. Budnik-Rodz, "Low rate energy use for heating and in industrial energy supply systems-Some technical and economical aspects," Energy, vol. 31, no. 14, pp. 2252-2267, 2006.

[6] A. Sözen and H. S. Yücesu, "Performance improvement of absorption heat transformer," Renewable Energy, vol. 32, no. 2, pp. 267-284, 2007.

[7] J. Yin, L. Shi, M. Zhu, and L. Han, "Performance analysis of an absorption heat transformer with different working fluid combinations," Applied Energy, vol. 67, no. 3, pp. 281-292, 2000.

[8] K. Parham, M. Yari, and U. Atikol, "Alternative absorption heat transformer configurations integrated with water desalination system," Desalination, vol. 328, pp. 74-82, 2013.

[9] M. Khamooshi, K. Parham, F. Egelioglu, M. Yari, and H. Salati, "Simulation and optimization of novel configurations of triple absorption heat transformers integrated to a water desalination system," Desalination, vol. 348, pp. 39-48, 2014.

[10] V. Zare, M. Yari, and S. M. S. Mahmoudi, "Proposal and analysis of a new combined cogeneration system based on the GT-MHR cycle," Desalination, vol. 286, pp. 417-428, 2012.

[11] M. Yari, "A novel cogeneration cycle based on a recompression supercritical carbon dioxide cycle for waste heat recovery in nuclear power plants," International Journal of Exergy, vol. 10, no. 3, pp. 346-364, 2012.

[12] J. Siqueiros and R. J. Romero, "Increase of COP for heat transformer in water purification systems-part I: increasing heat source temperature," Applied Thermal Engineering, vol. 27, no. 5-6, pp. 1043-1053, 2007.

[13] R. J. Romero, J. Siqueiros, and A. Huicochea, "Increase of COP for heat transformer in water purification systems. Part IIwithout increasing heat source temperature," Applied Thermal Engineering, vol. 27, no. 5-6, pp. 1054-1061, 2007.
[14] J. A. Hernández, A. Bassam, J. Siqueiros, and D. Juárez-Romero, "Optimum operating conditions for a water purification process integrated to a heat transformer with energy recycling using neural network inverse," Renewable Energy, vol. 34, no. 4, pp. 1084-1091, 2009.

[15] J. A. Hernández, D. Juárez-Romero, L. I. Morales, and J. Siqueiros, "COP prediction for the integration of a water purification process in a heat transformer: with and without energy recycling," Desalination, vol. 219 , no. $1-3$, pp. 66-80, 2008.

[16] Z. Zhao, Y. Ma, and J. Chen, "Thermodynamic performance of a new type of double absorption heat transformer," Applied Thermal Engineering, vol. 23, no. 18, pp. 2407-2414, 2003.

[17] Z. Zhao, F. Zhou, X. Zhang, and S. Li, "The thermodynamic performance of a new solution cycle in double absorption heat transformer using water/lithium bromide as the working fluids," International Journal of Refrigeration, vol. 26, no. 3, pp. 315-320, 2003.

[18] H. Martínez and W. Rivera, "Energy and exergy analysis of a double absorption heat transformer operating with water/lithium bromide," International Journal of Energy Research, vol. 33, no. 7, pp. 662-674, 2009.

[19] I. Horuz and B. Kurt, "Single stage and double absorption heat transformers in an industrial application," International Journal of Energy Research, vol. 33, no. 9, pp. 787-798, 2009.

[20] R. Gomri, “Thermal seawater desalination: possibilities of using single effect and double effect absorption heat transformer systems," Desalination, vol. 253, no. 1-3, pp. 112-118, 2010.

[21] R. Gomri, "Energy and exergy analyses of seawater desalination system integrated in a solar heat transformer," Desalination, vol. 249, no. 1, pp. 188-196, 2009.

[22] K. Parham, U. Atikol, M. Yari, and O. P. Agboola, "Evaluation and optimization of single stage absorption chiller using $(\mathrm{LiCl}+$ $\mathrm{H}_{2} \mathrm{O}$ ) as the working pair," Advances in Mechanical Engineering, vol. 2013, Article ID 683157, 8 pages, 2013.

[23] I. Horuz, "A comparison between ammonia-water and waterlithium bromide solutions in vapor absorption refrigeration systems," International Communications in Heat and Mass Transfer, vol. 25, no. 5, pp. 711-721, 1998.

[24] J. Sun, L. Fu, and S. Zhang, "A review of working fluids of absorption cycles," Renewable and Sustainable Energy Reviews, vol. 16, no. 4, pp. 1899-1906, 2012.

[25] M. Khamooshi, K. Parham, and U. Atikol, "Overview of ionic liquids used as working fluids in absorption cycles," Advances in Mechanical Engineering, vol. 2013, Article ID 620592, 7 pages, 2013.

[26] K. Parham, M. Khamooshi, D. B. K. Tematio, M. Yari, and U. Atikol, "Absorption heat transformers-a comprehensive review," Renewable and Sustainable Energy Reviews, vol. 34, pp. 430-452, 2014.

[27] P. Donnellan, E. Byrne, and K. Cronin, "Internal energy and exergy recovery in high temperature application absorption heat transformers," Applied Thermal Engineering, vol. 56, no. 1-2, pp. 1-10, 2013.

[28] P. Donnellan, E. Byrne, J. Oliveira, and K. Cronin, "First and second law multidimensional analysis of a triple absorption heat transformer (TAHT)," Applied Energy, vol. 113, pp. 141-151, 2014.

[29] R. Best and W. Rivera, "Thermodynamic design data for absorption heat transformers. Part six: operating on watercarrol," Heat Recovery Systems \& CHP, vol. 14, no. 4, pp. 427436, 1994. 
[30] M. A. R. Eisa, R. Best, and F. A. Holland, “Thermodynamic design data for absorption heat transformers-Part II. Operating on water-calcium chloride," Journal of Heat Recovery Systems, vol. 6, no. 6, pp. 443-450, 1986.

[31] W. Rivera, J. Cerezo, R. Rivero, J. Cervantes, and R. Best, "Single stage and double absorption heat transformers used to recover energy in a distillation column of butane and pentane," International Journal of Energy Research, vol. 27, no. 14, pp. 12791292, 2003.

[32] S. A. Klein and F. Alvarado, Engineering Equation Solver, Version 9.237, F-Chart Software, Middleton, Wis, USA, 2012.

[33] W. Rivera, M. J. Cardoso, and R. J. Romero, "Single-stage and advanced absorption heat transformers operating with lithium bromide mixtures used to increase solar pond's temperature," Solar Energy Materials and Solar Cells, vol. 70, no. 3, pp. 321333, 2001.

[34] M. Ahachad, M. Charia, and A. Bernatchou, "Solar absorption heat transformer applications to absorption refrigerating machines," International Journal of Energy Research, vol. 17, no. 8, pp. 719-726, 1993.

[35] X. Zhang and J. Li, "Exergy analysis of double absorption heat transformers with a new solution cycle," Journal of Dalian University of Technology, vol. 47, no. 3, pp. 333-337, 2007.

[36] T. G. Kolda, R. M. Lewis, and V. Torczon, "Optimization by direct search: new perspectives on some classical and modern methods," SIAM Review, vol. 45, no. 3, pp. 385-482, 2003.

[37] W. Rivera, A. Huicochea, H. Martínez, J. Siqueiros, D. Juárez, and E. Cadenas, "Exergy analysis of an experimental heat transformer for water purification," Energy, vol. 36, no. 1, pp. 320-327, 2011.

[38] S. Sekar and R. Saravanan, "Experimental studies on absorption heat transformer coupled distillation system," Desalination, vol. 274, no. 1-3, pp. 292-301, 2011.

[39] R. J. Romero and A. Rodríguez-Martínez, "Optimal water purification using low grade waste heat in an absorption heat transformer," Desalination, vol. 220, no. 1-3, pp. 506-513, 2008.

[40] L. Garousi Farshi, S. M. Seyed Mahmoudi, and M. A. Rosen, "Analysis of crystallization risk in double effect absorption refrigeration systems," Applied Thermal Engineering, vol. 31, no. 10, pp. 1712-1717, 2011. 


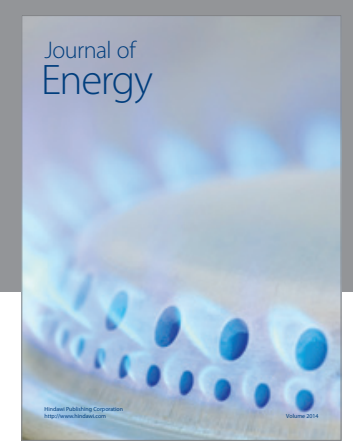

Journal of

Industrial Engineering
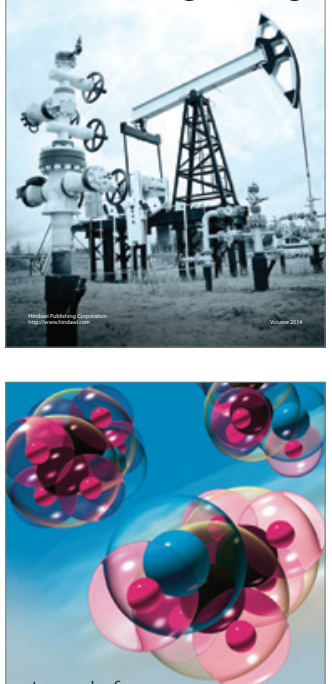

Fuels
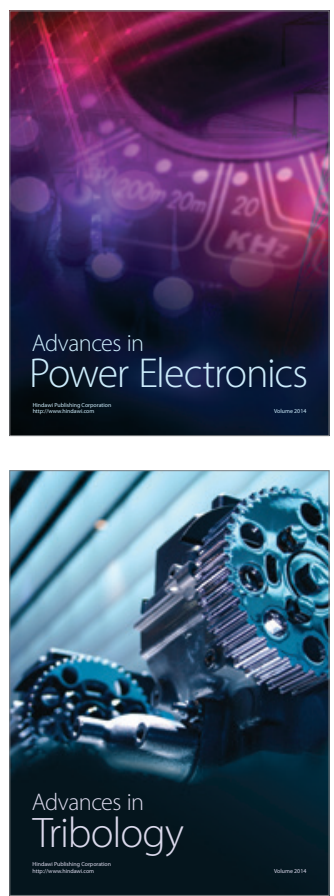

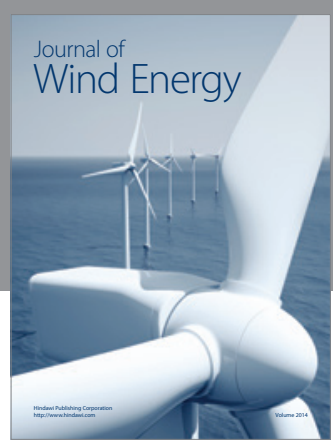

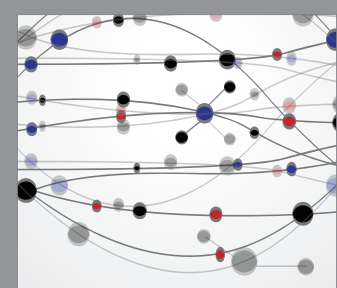

The Scientific World Journal

Submit your manuscripts at http://www.hindawi.com

Journal of

Structures
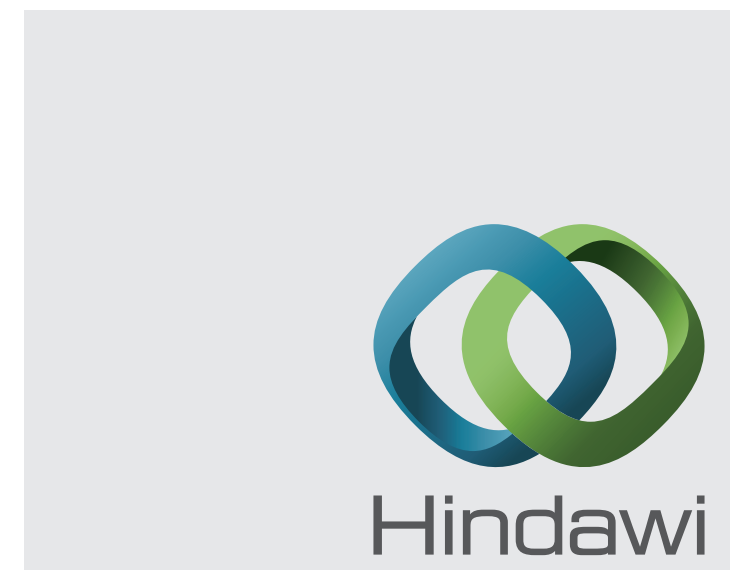

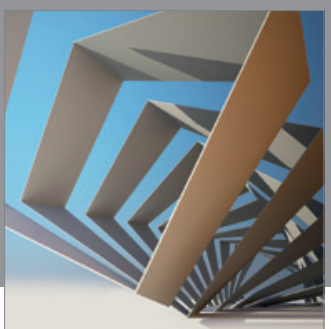

Rotating

Machinery
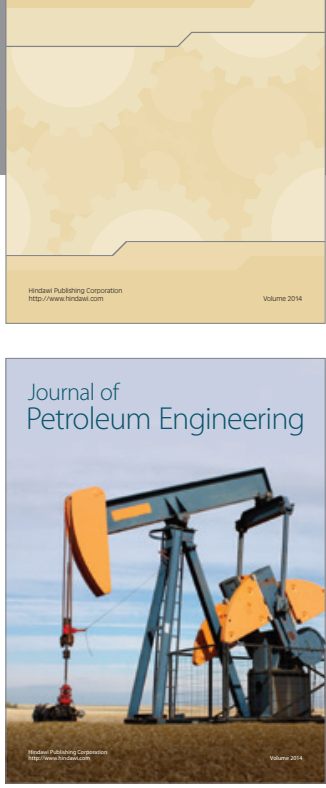

Journal of

Solar Energy
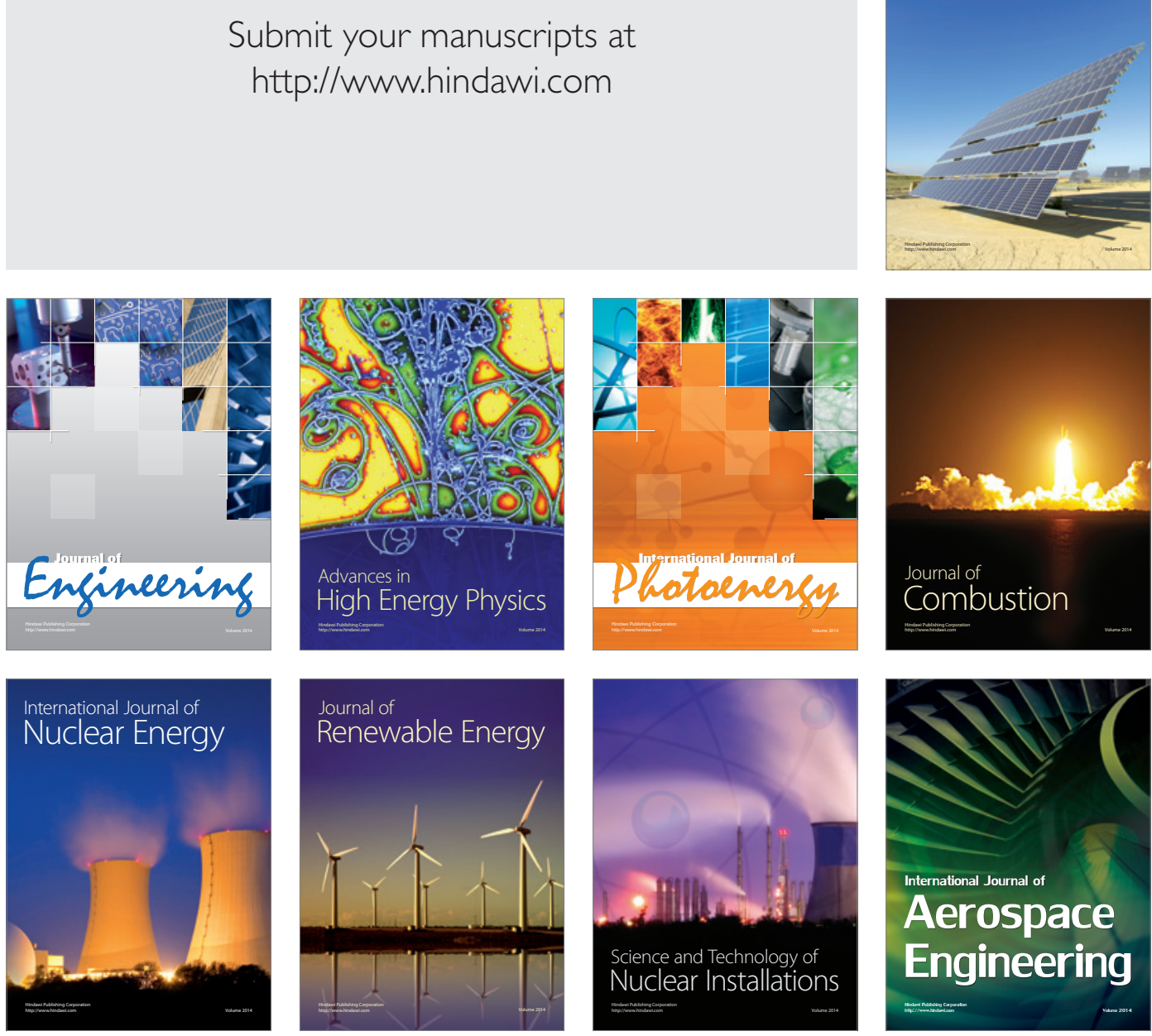